\title{
NAS LENTES DA AÇÃO SOCIAL COMO MARKETING
}

\author{
BRUM,Michele da Silva Brum; Acadêmica do Curso Design Digital; Universidade Federal de Pelotas \\ msbrum@gmail.com \\ ANGELI,Juliana Corrêa Hermes Angeli;Mestre; Universidade Federal de Pelotas \\ julianaangeli@gmail.com
}

\author{
Palavras-Chave: Fotografia,exposição,ação,marketing \\ Resumo: \\ Esse trabalho propõe pensar, a partir de uma exposição realizada em 2015 a fotografia como ferramenta \\ para ações sociais, e também como forma de consolidação de uma marca. O evento "Tons de Mães", \\ trouxe como objetivo a idéia do caráter social como principal objetivo e paralelo a solidificação de uma \\ marca atráves de uma exposição.
}

\section{Introdução}

O contexto da sociedade atual, mergulhada na globalização da economia, no fluxo comunicativo e na interação contínua, tem traçado mudanças profundas nas visões sobre a própria sociedade. O presente trabalho é o resultado de uma exposição de ensaios fotográficos realizados em estúdio, em 2015, e que consistiu em uma ação coletiva para arrecadar fraldas que foram doadas para o Hospital São Francisco de Paula, em Pelotas. A fotografia integra a ferramenta de ação para a campanha tendo o objetivo de construir e interagir com a sociedade, em um projeto social. Neste propósito, foram selecionadas mães através da mídia social facebook, e foram realizados ensaios fotográficos delas com seus filhos. Na abertura da exposição, modelos e público, foram convidados a doarem um pacote de fraldas descartáveis para serem doados.

Sabe-se que a partir de um ensaio fotográfico, o idealizador do projeto através do material constituído poderá futuramente desenvolver campanhas que vão desde um banner até a um aplicativo. O público alvo da campanha será de mães e filhos de ambos os sexos. Por ser uma campanha ideológica, não possui concorrentes, porém há vários segmentos que se utilizam dessa estratégia potencializando outros projetos com o mesmo objetivo.

\section{Fotografia Social}

Fotografia é a arte de escrever com luz. Uma perfeita combinação entre luzes e sombras captadas por frações de segundos, transformando-se em elementos visíveis, únicos e interpretáveis das mais diferentes formas, dependendo do repertório do observador. O termo fotografia tem origem grega: foto = luz, grafia = escrita (LIMA, 1988, p. 7 apud RODRIGUES, 2007. p. 69). A fotografia vem com a capacidade de guardar para a posterioridade imagens importantes para a ciência, a história, a religião e os infinitos feitos do homem. A primeira fotografia foi realizada por Joseph Nicéphore Niépce, na data de 1826, que conseguiu depois de 10 anos de tentativas, captar a vista da janela do sótão de sua casa em Charles-sur-Saône. (BUSSELLE, 1977, p. 30). A exposição Tons de Mães é um projeto com o objetivo de desenvolver ações que utilizam a imagem fotográfica como vetor para a promoção da ação coletiva, através da fotografia e do design. A iniciativa possibilita o desenvolvimento de ações capazes de modificar contextos e espaços, imprimindo à fotografia o status de democratização da informação, instrumento de arte, reflexão e construção da 


\section{SULDESIGN CIENTÍFICO 2017}

VIII Suldesign - encontro sul-americano

identidade. O público participante é provocado a refletir sobre suas experiências de vida, eternizar um momento especial, fortalecendo sua identidade, das suas famílias e da sua comunidade.

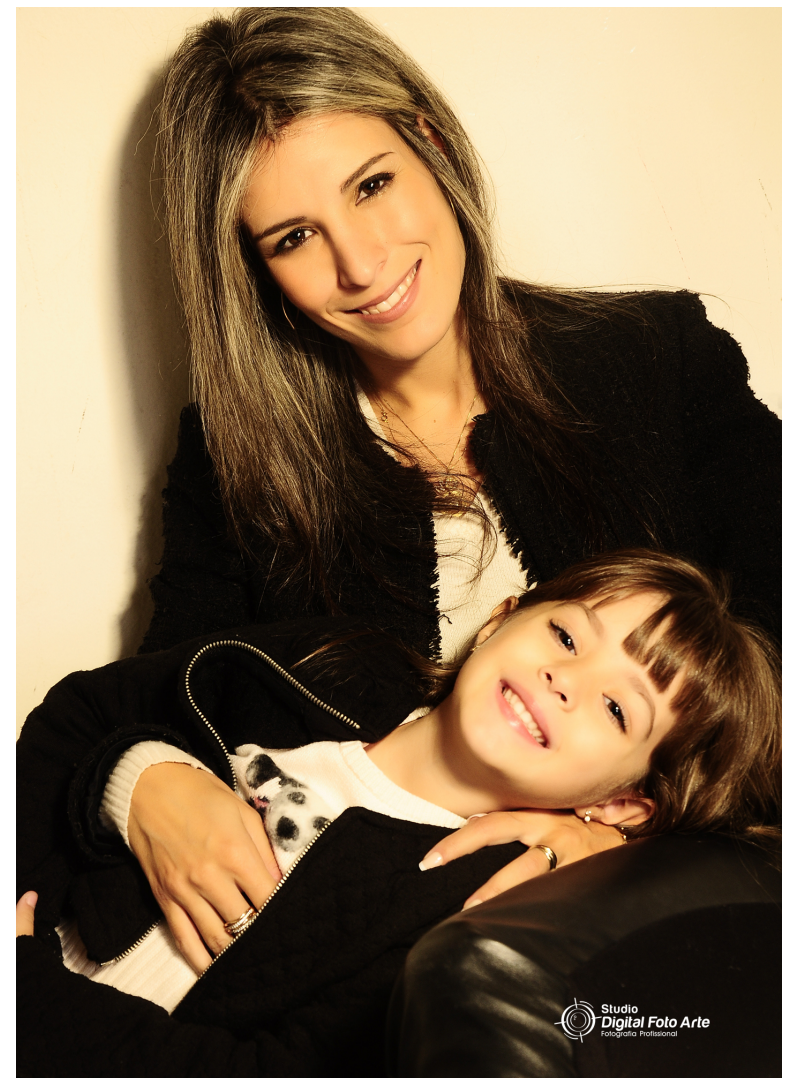

IMAGEM DO ENSAIO

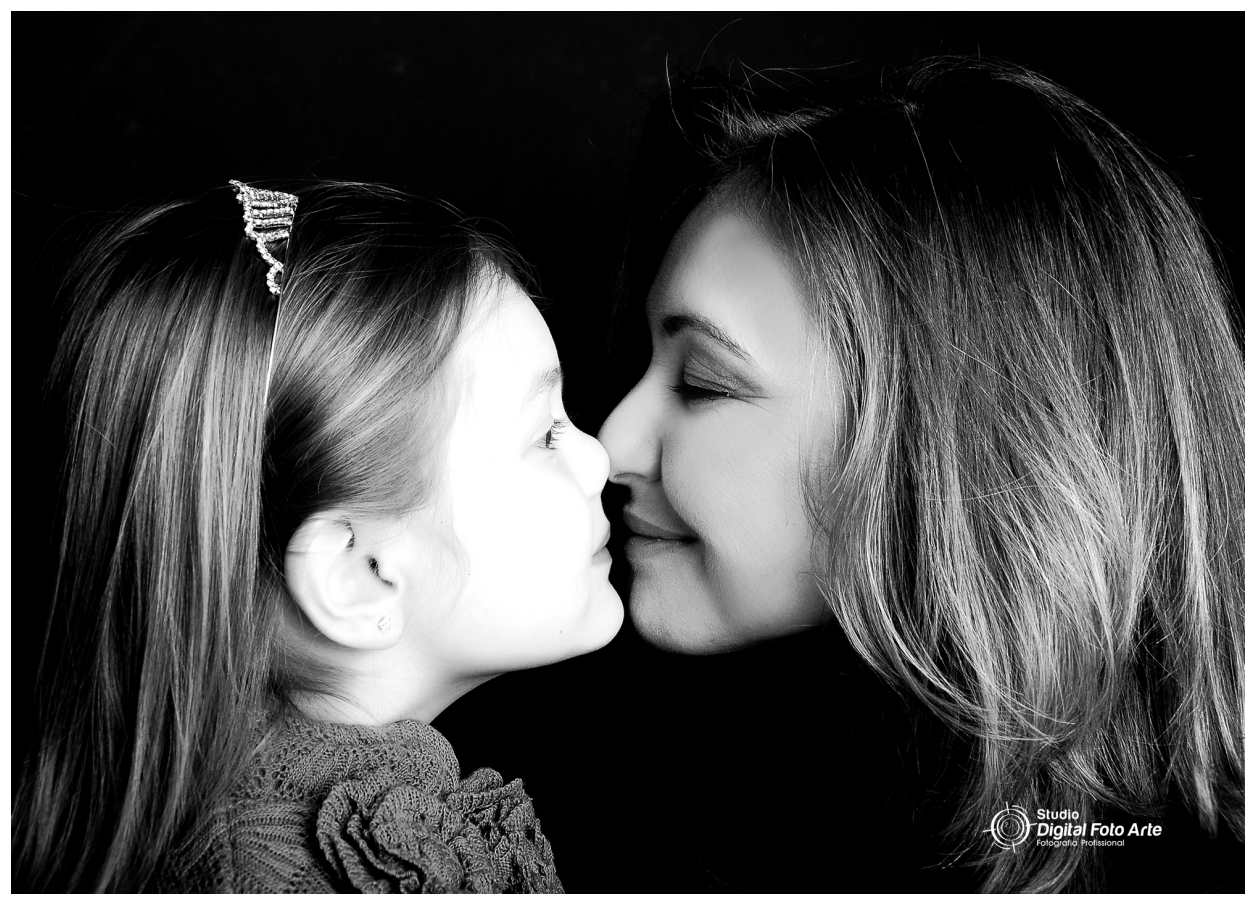

\section{UFPEL}




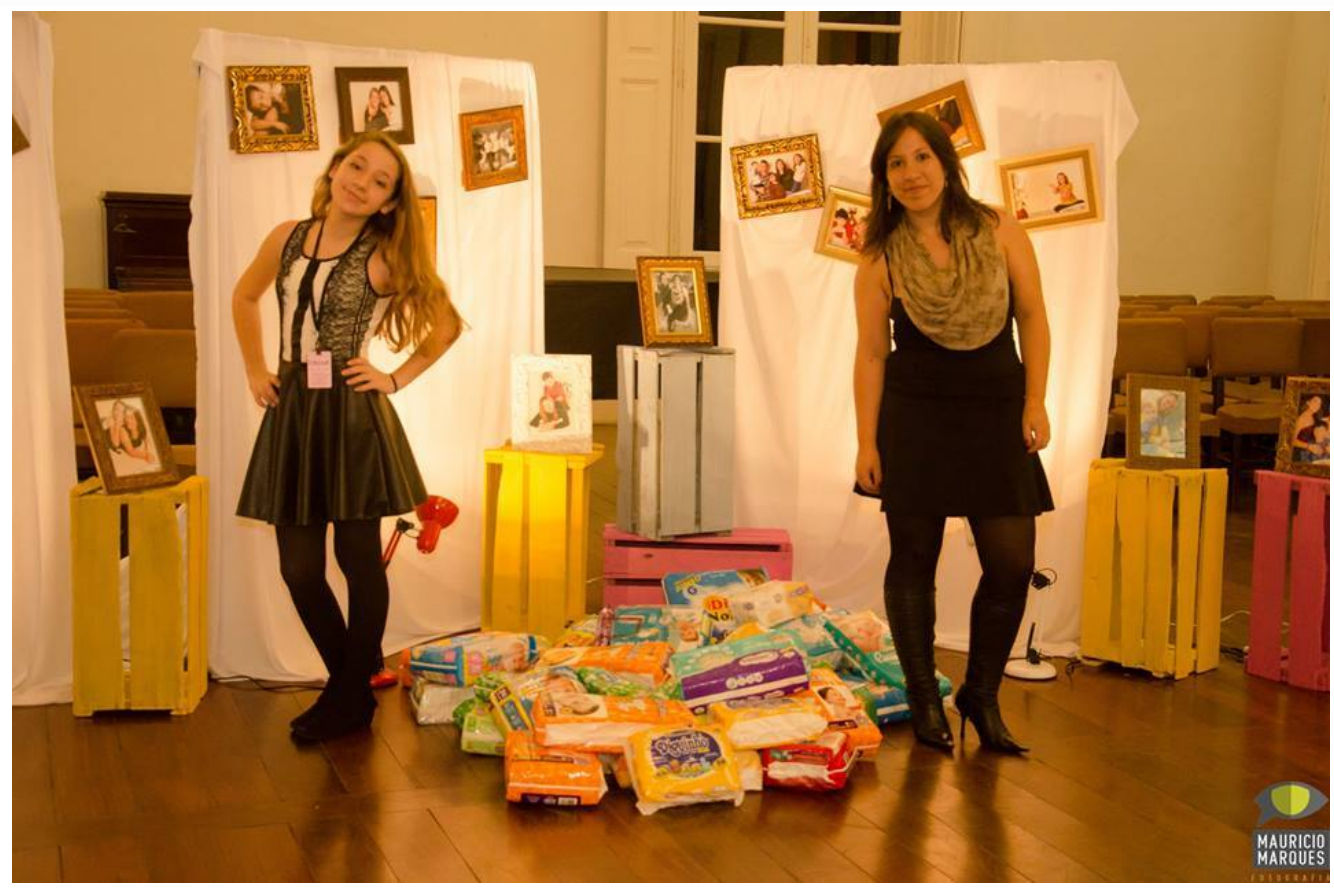

RESULTADO DA EXPOSIÇÃO

\section{Consolidação da Marca}

A aproximação marca/cliente, através de uma exposição possibilita que a ação seja realizada de forma imperceptível para o consumidor, criando meios que aproximam o consumidor e a empresa. Enquanto a propaganda trabalha com atitude, a exposição trabalha com o comportamento do público dentro de um estilo de vida próprio, para criar um vínculo com o seu consumidor. A comunicação dirigida proporciona a escolha da ferramenta mais adequada, individualizando o formato da mensagem, estimulando o relacionamento com os diversos públicos de interesse da empresa ou instituição e, com isso, obtêm resultados mais eficientes a um custo menor. Sendo assim a exposição foi além de uma ação social, um instrumento utilizado para atingir o público-alvo desejado, divulgar uma marca, pois fortalece o relacionamento e reforça a imagem da marca.

\section{Referências}

Imaginário Coletivo.Acessado em 24 de abril de 2017.Online.Disponível em :

http://www.imaginariocoletivo.org/index.php/sobre/

Portal do Marketing. A Importância dos Eventos para a consolidação de uma marca. Acessado em 24 de abril de 2017.Online. Disponível em :

http://www.portaldomarketing.com.br/Artigos1/Importancia dos eventos para_a consolidacao de uma marca.htm

RODRIGUES, Ricardo Crisafulli.. / Ricardo Crisafulli Rodrigues. Ci. Inf., Brasília, Análise e tematização da imagem fotográfica v. 36, n. 3, p. 67-76, set./dez. 2007

BUSSELLE, Michael. Tudo sobre fotografia / Michael Busselle - São Paulo: Círculo do Livro S.A. 1977 